\title{
Contemporary Methods for Production of Ultramarine
}

\author{
A.V. Vyboishchik ${ }^{1, a^{*}}$ and M.Yu. Popov ${ }^{1, b}$ \\ ${ }^{1}$ South Urals State University, 76 Lenin Ave., Chelyabinsk 454080, Russia \\ aalex_vyb@list.ru, bpmik0@yandex.ru
}

Keywords: Ultramarine, Ultramarine Blue, Ultramarine Green, Kaoline, Diatomite, Malleablizing

\begin{abstract}
The article describes the features of ultramarine, its modifications, viz. ultramarine blue. The requirements for ultramarine blue grades are observed, the one-stage and two-stage technologies for the production of ultramarine blue are described, the advantages and disadvantages of both methods are listed, new recommendations for the production of ultramarine blue are offered.
\end{abstract}

\section{Introduction}

Ultramarine is a natural pigment applied since the middle ages [1, 2, 3]. Chemically, ultramarine is a sodium aluminosilicate of the chemical composition $\left(\mathrm{Na} 2 \mathrm{O} \cdot \mathrm{Al}_{2} \mathrm{O}_{3} \cdot \mathrm{mSiO}_{2}\right) \cdot \mathrm{x} \cdot \mathrm{Na}_{2} \mathrm{Sn}$ containing sodium sulphides and polysulphides. This inorganic pigment is found naturally as a lazurite mineral in various mountainous countries extracted from lapis lazuli rocks $[4,5]$ and, due to the time-consuming extracting process, is very expensive [6].

The applications of ultramarine are as follows: the production of plastics, paints, powder coatings, rubber and thermoplastic elastomers, detergents, cosmetics and soaps, art colours, leather finishes, synthetic fibers, etc.

Ultramarine, depending on customer needs, comes in the following colour modifications: ultramarine blue, ultramarine green, ultramarine purple and ultramarine red, of which ultramarine blue has found the widest application in various industries $[7,8,9,10,11,12]$.

\section{Properties of Ultramarine Blue Grades}

Blue ultramarine having the composition of $\mathrm{m}=2.5 \ldots 3.0 ; \mathrm{n}=2 \ldots 5, \mathrm{x}=2.5 \ldots 3.0$, is produced in the following grades $[13,14]$ as shown in Table 1.

Table 1. Basic requirements for ultramarine grades

\begin{tabular}{|l|l|l|l|l|l|}
\hline \multirow{2}{*}{ Parameter } & \multicolumn{5}{c|}{ Ultramarine grade } \\
\cline { 2 - 7 } & UHK-A & UHK & US & UM-1 & UM-2 \\
\hline Mass content of sulphur, no more than [\%] & 0.02 & 0.03 & 0.10 & 0.6 & 0.75 \\
\hline Intensity in relation to the standard, no less than [\%] & 240 & 200 & 180 & 140 & 120 \\
\hline $\begin{array}{l}\text { Ratio of the remainder after wet sieving, no more } \\
\text { than [\%] }\end{array}$ & - & & & & \\
0056K & 0.75 & 0.1 & 0.1 & 0.7 & 10 \\
0045K & - & - & - & - & - \\
$016 \mathrm{~K}$ & & - & - & - & 0.03 \\
\hline
\end{tabular}


UHK-A ultramarine grade is applied in art watercolours, UHK grade is applied in all other art colours, the US grade is applied in sugar production, UM-1 and UM-2 grades are applied in paintand-varnish and other industries. In oxidizing environment, ultramarine is stable up to $300^{\circ} \mathrm{C}$, and it does decompose up to $500 \ldots 600^{\circ} \mathrm{C}$, whereas and in carbonic environment it is stable even at $700^{\circ} \mathrm{C}$. The quality parameters of ultramarine are significantly affected by the chemical composition of the used raw materials and the production technology.

\section{Methods for the Production of Ultramarine Blue}

Ultramarine is yielded from kaoline having the chemical formula $\mathrm{Al}_{2} \mathrm{O}_{3} \cdot 2 \mathrm{SiO}_{2} \cdot 2 \mathrm{H}_{2} \mathrm{O}[5,6,13]$, and also diatomite, sulphur and sodium carbonate as raw materials by means of heat treatment. All the above-listed raw materials must match the following requirements:

1. All the raw materials must be dry to avoid decomposition of the resulting sodium polysulphides.

2. The soda must not contain bicarbonates.

3. The kaoline and diatomite must not have iron impurities.

4. The sulphur must not contain arsenic.

The ratio of the raw materials used in ultramarine charge is maintained within the following requirements $[13,14]$ as given in table 2 .

Table 2. The formulation of raw materials in ultramarine charges [\%]

\begin{tabular}{|l|l|l|l|}
\hline \multicolumn{1}{|c|}{ Raw material } & \multicolumn{1}{c|}{ Charge \#1 } & \multicolumn{1}{c|}{ Charge \#2 } & \multicolumn{1}{c|}{ Base material } \\
\hline Kaoline & 30.3 & 25.6 & 96.9 \\
\hline Sulphur & 29.4 & 34.6 & 99.5 \\
\hline Soda ash & 28.9 & 28.8 & 97.7 \\
\hline Diatomite & 5.5 & 7.5 & 86.9 \\
\hline Pitch & 3.6 & 3.5 & 97.8 \\
\hline
\end{tabular}

Ultramarine is yielded not only from kaodine, but also from amorphous sodium alumosilicate, the mixture of sodium aluminate and silica, the mixture of amorphous alumina and silicon dioxide, as well as from the mixture of aluminuim-containing and siliferous waste after special treatment $[15,16,17,18,19,20,21]$. For example, while yielding UM-1 and UM-2 ultramarine grades, silicon is substituted with ferrosilicon dust, technical sodium aluminate is substituted with alkalineetched aluminium products, and while yielding UHK and UHK-A ultramarine grades, amorphous aluminium is substituted with dead aluminuim-containing catalyst.

The heat treatment of ultramarine charge is performed in either the one-stage or the two-stage technology.

According to the one-stage technology, the charge is fed from the fireclay into the porous crucibles, with each crucible containing a specified amount of charge. The crucibles are installed in the furnace in rows, one on top of the other. The roasting process consists of three steps.

The first step proceeds from the beginning of the roasting process during the furnace temperature increase up to $450^{\circ} \mathrm{C}$, without air access in the reducing medium. The result of the first step is the obtaining of sodium sulphides and polysulphides.

The second step proceeds during the reaction of polysulphides (obtained at the first step) with kaoline, and during the furnace temperature increasing to $725 \ldots 780^{\circ} \mathrm{C}$, without air access into the reducing medium, and with the attained temperature maintained for several hours. The result of the second step is the obtaining of ultramarine green. 
The third step, also known as malleablizing, proceeds during the oxidation of ultramarine green (obtained at the second step), and during the furnace cooling with atmospheric oxygen access, which is maintained for $8 \ldots 15$ days. The result of the third step is the obtaining of ultramarine blue.

The main disadvantage of the one-stage technology is the yielding of a heterogeneous product, which is due to the uneven furnace temperature. Another disadvantage of the one-stage technology is its long duration, which is very time-consuming. The two-stage technology, which is invented recently, obtains ultramarine green and ultramarine blue separately with the overall process duration decreasing to $40 \ldots 50$ hours, which is $2 \ldots 8$ times less time-consuming than the one-stage technology.

As a result of either of the two above-described technologies, only a semi-finished ultramarine product is yielded, which requires further washing from impurities, drying and, finally, grinding.

Besides, other disadvantages of the above-described technology of yielding ultramarine are, firstly, the process stoppability, or discontinuity; secondly, the application of ball mills for grinding raw materials and semi-finished products, thus providing insufficient dispersion of the products; and, thirdly, comparatively low drying temperatures of $150 \ldots 200^{\circ} \mathrm{C}$ in drum dryers, thus reducing the process productivity.

In this regard, the introduction of a continuous process for yielding ultramarine with the use of advanced types of equipment, such as bead mills and combined spray dryers, will increase not only the process productivity, but also the final product quality.

\section{Conclusions}

The above-stated research allow us to make the following conclusions.

1. Ultramarine is a pigment used in various industries.

2. Ultramarine blue, as the most applicable ultramarine pigment, is traditionally yielded by the one-stage technology consisting of heating, reducing and malleablizing steps.

3. The disadvantage of the one-stage technology is the long process duration equal to $8 \ldots 15$ days due to the malleablizing step.

4. The invented two-stage technology separates the yielding processes of ultramarine green and ultramarine blue, and reduces the overall process duration to $40 \ldots 50$ hours.

\section{References}

[1] Gerhard Pfaff, Ultramarine pigments, Physical Sciences Reviews, 2021. https://doi.org/10.1515/psr-2020-0201

[2] Pawel Rejmak, Structural, Optical and Magnetic Properties of Ultramarine Pigments: A

DFT Insight, The Journal of Physical Chemistry C. 122(51) (2018). https://doi.org/10.1021/acs.jpcc.8b09856

[3] Stanislaw Kowalak, Aldona Jankowska, Sabina $\measuredangle$, Preparation of various color ultramarine from zeolite A under environment-friendly conditions, Catalysis Today. 90(1) (2004) 167-172. https://doi.org/10.1016/j.cattod.2004.04.023

[4] Robert Coenraads, Claudio Canut de Bon, Lapis Lazuli from the Coquimbo Region, Chile, Gems and Gemology. 36(1) (2000) 28-41. https://doi.org/10.5741/GEMS.36.1.28

[5] Jose Pedro Sancho, Oscar Restrepo, P. García, J. Ayala, B. Fernández, Luis Felipe Verdeja, Ultramarine blue from Asturian "hard" kaolins, Applied Clay Science. 41(3-4) (2008) 133. https://doi.org/10.1016/j.clay.2007.10.005 
[6] Vahideh Tajer Kajinebaf, Fereshteh Rezaeian, Masoud Rajabi, Saeid Baghshahi, Replacing nano-clay for kaolin in ultramarine pigments, Pigment and Resin Technology. 43(1) (2013). https://doi.org/10.1108/PRT-03-2013-0020

[7] N. Gobeltz, A. Demortier, J.-P. Lelieur, A. Lorriaux, C. Duhayon, Presence of iron(III) impurities in ultramarine green pigments, New Journal of Chemistry. 20(1) (1996) 19-22.

[8] Eleanor Cato, Antonella Rossi, Nadim C Scherrer, Ester S.B Ferreira, An XPS study into sulphur speciation in blue and green ultramarine, Journal of Cultural Heritage. (2017). https://doi.org/10.1016/j.culher.2017.09.005

[9] Costanza Miliani, Alessia Daveri, Bruno Brunetti, Antonio Sgamellotti, CO2 entrapment in natural ultramarine blue, Chemical Physics Letters. 466(s 4-6) (2008) 148-15. https://doi.org/10.1016/j.cplett.2008.10.038

[10]Eleanor Cato, Nadim C Scherrer, Ester S.B Ferreira, Raman mapping of the S 3 chromophore in degraded ultramarine blue paints, Journal of Raman Spectroscopy. 48(11) (2017). https://doi.org/10.1002/jrs.5256

[11] Lucy Goncalves, D. Moronta, Freddy Ocanto, Carlos Linares, Synthesis of ultramarine blue type pigments using several raw materials, Revista de la Facultad de Ingenieria. 25(1) (2010) 25 31.

[12] Dafna Arieli, David E. W. Vaughan, D Goldfarb, New Synthesis and Insight into the Structure of Blue Ultramarine Pigments, Journal of the American Chemical Society. 126(18) (2004) 5776-88. https://doi.org/10.1021/ja0320121

[13] A. I. Shereshevsky, T. P. Unanjanc, G. Ya. Baharovsky, Himicheskie tovary (Chemical Products) (Goshimizdat, Moscow, 1961)

[14] O. V. Orlova, T. N. Fomicheva, Tehnologiya lakov i krasok (Technology of Varnishes and Paints) (Himiya, Moscow, 1990)

[15] A.U. Rahman, F. Khan, M. Riaz, A. Latif, Synthesis of blue pigment from kaolin, Pakistan Journal of Scientific and Industrial Research. 52(1) (2009) 15-17.

[16] Ashok Borhade, G. Dholi Arun, G. Wackchaure Sanjay, R. Tope Dipak, Synthesis of intense blue ultramarine from coal fly ash as an aluminosilicate source under environment- Friendly conditions, Research Journal of Chemistry and Environment. 17(1) (2013) 14-20.

[17] Ashok Borhade, Tushar Kshirsagar, Arun G. Dholi, Novel synthesis of ultramarine blue from waste coal fly ash via thiocyanate aluminosilicate sodalite, Journal of Sulfur Chemistry. (2016). https://doi.org/10.1080/17415993.2016.1173215

[18] Yin-Hsiu Hsiao, yu-How Shen, Dah-Tong Ray, Synthesis of Ultramarine from Reservoir Silts, Minerals. 7(5) (2017). https://doi.org/10.3390/min7050069

[19] Haibo Wang, Shan Zhang, Hu Songyuan, Zhiwei Zhen, Mario A Gomez, Shuhua Yao, A systematic study of the synthesis conditions of blue and green ultramarine pigments via the reclamation of the industrial zeolite wastes and agricultural rice husks, Environmental Science and Pollution Research. 27(2-3) (2020). https://doi.org/10.1007/s11356-020-07624-8 [20]D. G. Booth, S. E. Dann, Mark T. Weller, The effect of the cation composition on the synthesis and properties of ultramarine blue, Dyes and Pigments. 58(1) (2003) 73-82. https://doi.org/10.1016/S0143-7208(03)00037-8 [21] Andreas A. Landman, Danita de Waal, Fly ash as a potential starting reagent for the synthesis of ultramarine blue, Materials Research Bulletin. 39(4-5) (2004) 655-667. https://doi.org/10.1016/j.materresbull.2003.12.002 